A. $766.5^{-\infty}$ ox

THE PRINCIPLES OF CLASSIFICATION

IN

\title{
THE ANIMAL KINGDOM;
}

ox

THE STRUCTURE OF

THE HALCYONOID POLYPI;

ON

THE MORPHOLOGY OF

T II $\mathrm{E}$ M E D U S E.

BY LOUIS AGASSIZ,

PROFESSOR OF ZOÖLOGT AND GEOLOGI IN THE LAWRENCE SCIENTTIFIO SCHOOL, HARVARD UNIVERSITY. 


4. Dhituran

Lexpyzy '16. 



\section{THE PRINCIPLES OF CLASSIFICATION}

IN

\section{THE ANIMAL KINGDOM;}

ON

THE STR U T U R O F

\section{THE HALCYONOID POLYPI;}

ON

THE MORPHOLOGY OF

T H E M E D U S

BY LOUIS AGASSIZ,

PROFESSOR OF ZOÖLOGY AND GEOLOGY IN THE LAWRENCE SCIENTIFIC SCHOOL, HARVARD UNIVERSITY.

From Proccedings of the Third Meeting of the American Association for the Advancement of Science, held at Charleston, March, 1850.

CHARLESTON, S. C. STEAM-POWER PRESS OF WALKER AND JAMES. 



\section{ON THE PRINCIPLES OF CLASSIFICATION.}

IT may be said that investigations upon the structure of animals have already yielded all the information coming from this source which can serve to improve our classification of the animal kingdom.

After the great natural divisions of the animal kingdom have been circumscribed in accordance with their anatomical structure; after the classes of the animal kingdom have been characterized by organic differences, it is hardly possible to expect that further investigations upon the structure of animals will afford the means of establishing correctly the natural relations of the families. For it is already seen that the amount of organic difference which exists between the different families is either too insignificant to afford a test by which to settle their pre-eminence or inferiority, or so striking as to impress us with an exaggerated idea of their indifference. Many examples could be quoted to show, that, in this respect, from the same identical facts, naturalists have arrived at very opposite conclusions. And this diversity of opinion among investigators of equal ability, leads me to think that comparative anatomy has done its work in that direction, and that we must seek for another principle in order to settle in a natural way the respective positions of the minor divisions throughout the animal kingdom, and to set aside, once forever, the arbitrary decisions which we are constantly tempted to introduce into our classifications, whenever we attempt to arrange all the families in natural groups. Before so much had been done to improve the natural classification of the animal kingdom, it was hardly possible to notice how much was, on every occasion, settled by induction, and even arbitrary decision, beyond what the knowledge of facts would justify - for the brilliant results which the introduction 
of comparative anatomy, as the foundation of the classification of the animal kingdom, has brought to light, must naturally have blinded us to the imperfections and deficiencies which constantly accompany the most important improvements in the natural arrangement of every class. Nevertheless, our confidence in the possibility of ascertaining the natural relations of all animals has been increased by the growing agreement between the different systems; and there is no philosophical observer who has not noticed this process of gradual approximation towards a greater uniformity in the view taken by different observers of the natural affinities of animals, however concealed this agreement has often been in consequence of changes of name or transposition of the order in which the objects were introduced.

The time has, however, gone by, when the mere translation of family names, or of more general or minor divisions, into another language, could be presented as a new system, and the raising of a secondary division into the rank of a primary group, or the lowering of a primary division into a subordinate position, constituted an improvement in the knowledge of the natural relations of animals. Nothing short of a material addition to the information we possess respecting any group of animals, can now be considered as a real advance in Zoölogy.

It should be further considered that our object is not merely or chiefly to ascertain the structural relations of animals, but to know all the various relations which have been established between them, and which they sustain towards the world in which they live. The knowledge of the natural embryonic development-of the order of succession in geological times-of the geographical distribution upon the surface of our globe-and of the habits arising from their natural relations to the elements in which they live-all these considerations are of as great importance in our zoölogical studies as the knowledge of the structure and functions of their organs, to which, of late, more exclusive attention has been paid.

When comparing, in former years, the characters of fossil fishes, especially with a view of ascertaining their natural relations to the living types, I was struck with the fact that those of earlier ages presented many structural peculiarities, which occur only in the embryonic condition of the fishes of our days, and also that the older representatives of any family rank lower in comparison to their living representatives. 
This led me to infer that embryonic data might be applied with advantage to the correct appreciation of the natural relations of the various members of one and the same family, and perhaps also to the determination of the relative position of closely allied types.

Under this impression, I began to compare young animals of various families with the different types of the same family in their full grown condition, when I was forcibly struck with the close resemblance there is between the younger stages of development of such representatives as could otherwise be recognized as ranking high in their respective families, and the lower forms belonging to the same groups. This led naturally to the conclusion, that the change which animals undergo during their growth might safely be taken as a standard to determine the natural order of succession of all the representatives of any given type, within the limits in which the higher ones pass successively through transient forms, which the lower ones naturally present permanently in their full grown condition.

This principle, once ascertained, led to the result, upon more extensive investigations, that a complete knowledge of the metamorphoses of animals, from the earliest period of their embryonic development to the last change they undergo before reaching their mature condition, would afford, throughout the animal kingdom, a true measure by which to ascertain precisely, and without arbitrary decision on our own part, the natural relative position of all the minor groups of the animal kingdom.

Beginning the revision of the animal kingdom with the type of Articulata, it was not difficult, with these views, to ascertain that the Worms, as a natural type, rank lowest in this department, as they represent permanently a structural adaptation which is closely analogous to the earliest condition of the development of the Insects; that the Crustacea constitute a class intermediate between the Worms and Insects, and not superior to the Insects, as some naturalists would have them; inasmuch as the highest combination of their rings presents us with an arrangement similar to that of the pupa of Insects, in which the joints of the head and of the chest are combined in an immorable shield, as in the pupa of Insects, and in which the joints of the abdomen alone remain movable, is also the case among the highest Crustacea. The position of the Insects as the highest class can no longer be denied, when we consider that in them the body is at last divided into three distinct regions-head, chest and abdomen-and that the locomotive appendages, which, in the lower 
classes, are so numerous and uniform along the whole length of the body, are reduced to the region of the chest, and assume there a particular development.

Again, the transformation of the respiratory organs is an additional evidence in favor of such an arrangement, as will be admitted from the fact that Worms aud Crustacea have chiefly a branchial respiration, while in Insects it becomes aerial, in their perfect condition at least.

Once upon this track, it was easy to follow out the minor changes which these animals undergo during their final transformation, and to derive from the knowledge of these changes sufficient information to assign a definite position to all the subordinate groups in each of these classes. Taking the Insects, for instance, into special consideration, we ascertain readily that chewing Insects rank below the sucking tribes, as their larvæ are chewing worms, provided with powerful jaws, even in the case of those which, like Lepidoptera, have the most perfectly developed sucking apparatus in their mature condition.

Again, an investigation of the changes which the wings undergo in their formation, and the manner in which they are unfolded when the perfect insect is hatched, led to the discovery that Coleopterous Insects, far from ranking high, must be considered as lowest among Insects, inasmuch as the upper larval wings of Lepidoptera are a sort of elytra, which, after being cast in the last moulting, are succeeded by the more perfect membranous wing, which, in its turn, undergoes such a development as to assign to those Lepidoptera which have their wings folded backwards and enclosing the body a position below those in which the wings spread sideways, and the highest position to those which raise their wings upwards; so that these investigations have settled even the relative position of the secondary minor groups in each of these orders, and though, as yet, imperfectly traced out, they have at least shown the principle upon which a natural classification of these animals might be carried into the most minute details, without ever leaving any point to our arbitrary decision. Similar results have already been arrived at in other classes; as, for instance, among Medusæ, where naked-eyed Discophori, with alternate generations, must be considered as the lowest type, recalling, in one of their conditions, the appearances of the inferior class of polypi, when the covered-eyed Discophori, with their strobiloid generation, begins in its lowest state with a medusoid polyp.

Similar facts are known among Echinoderms, in which, among Cri. 
noids, the highest free forms begin with germs provided with a stem, thus assigning, on embryological grounds, a lower position to all those which are provided with a stem.

In the same manner has it been possible to determine the position of Bryozoa among Mollusca below Ascidiæ, upon the ground that their embryonic development is similar. It has been possible, in the same way to assign to Pteropoda a position inferior to that of Gasteropoda proper, and not intermediate between Gasteropoda and Cephalopoda, as anatomical investigations would seem to indicate. For it is now plain that the spreading appendages of the body of Pteropoda are not analogous to the long tentacles which encircle the head in Cuttle-fishes, but correspond to the vibratory rudders of the embryo in marine Gasteropoda.

Again, the position of Foraminiferæ, seems to me no longer doubtful. They are neither microscopic Cephalophoda, nor Polypi, as of late it has been generally. thought best to consider them, but constitute a truly embryonic type in the great division of Gasteropoda, exemplifying, in this natural division, in a permanent condition, the embryonic state of development of common Gasteropoda, during which the bulk of the yolk passes through the process of repeated divisions.

This principle-of embryological changes as a foundation of the natural classifications in the internal arrangement of all the minor groups in the natural classes of the animal kingdom-applies with equal success to the Vertebrata.

We need only contrast the successive changes of tailless Batrachians during their metamorphoses, with the permanent forms of the caudate and branchiate types in that order, to be satisfied that the relative rank of all these genera can in no way be better determined than by a direct comparison of the permanent forms of the whole group, with the successive changes in the embryonic condition of its higher types; and a comparison of the metamorphoses themselves, in the different genera, will leave no doubt as to which of them the highest rank should be assigned.

I have already, on other occasions, alluded to the improvements which are likely to be introduced into our classification of birds, upon considerations derived from embryological data. I may be permitted here to add, that even the classification of mammalia will receive decided improvements upon the consideration of their embryological changes. A single instance, even now, will at least show that the 
true relative rank of their families can be determined in that way. We need only compare, among true Carnivora, the Plantigrades, the Digitigrades, and the web-footed Seals, with the transformation of the limbs in the embryo of Cats and Dogs, to be satisfied that the order in which these animals are arranged by Cuvier, does not agree with their natural metamorphoses, and that the Plantigrades should rank below the Digitigrades, nearer to the Seals, and the Digitigrades highest; and the affinity of the Ice-Bear to the Seals will further sustain this statement.

These remarks will, at the same time, show that no investigations are at present more needed to improve our natural methods in classification, than a thorough study of young animals; and that an extensive illustration of the young of all the principal representations of the great natural groups in the Animal Kingdom, would, for the present, contribute more to the advance of Zoölogy, than any amount of description of new species.

But these investigations of young animals should be made with a full knowledge of their various relations, and with the view of ascertaining chiefly those Zoölogical peculiarities, which may illustrate more fully the value of all these relations.

There is another field of investigation hardly yet entered upon, which is likely to contribute largely to the improvement of our classification. I refer to the study of fossils, compared in their structural peculiarities, with the embryos of their living representatives. It has already been shown that many fossils of the earliest geological periods have a close resemblance to embryonic forms of the present day; and that, in their respective families, these fossils rank among the lower types.

This result, in itself, should be a sufficient inducement to trace this double relation, and to ascertain from as many fossils as possible, whenever they are sufficiently well preserved to allow of such comparisons, what is the extent of their analogy to embryonic forms, of the present period, and also, what is the amount of affinity they have to the lower types of their respective classes.

I would mention in this connection, the necessity of a revised comparison of the Trilobites, with the earliest stages of development of Crustacea, when it will be found, as I have already seen it, that almost all the genera of Trilobites seem to be the prophetic images, in a gigantic form, of the different types the Crustacea present in their embryonic state. The different degrees of development of these different types, when contrasted with each other, will go far to 
assign to each genus its appropriate rank. I venture even to say, that the time will come when the relative age of fossils, within certain limits, will be as satisfactory a guide in assigning them their normal position in a natural system, as the facts derived from the study of their structure, so intimate are the connections existing between all parts of the wonderful plan displayed in creation.

Little or no advantage has as yet been derived from the study of the relations of animals with the elements in which they live, in ascertaining their natural relations among themselves; but even in this respect we may derive valuable hints from a careful study of the geographical distribution of all animals; and the mere nature of the elements in which they live naturally.

On reviewing lately the whole Animal Kingdom, with a view to ascertain what is the value of the natural comnection between the animals and the media in which they live, with reference to organic gradation, I have satisfied myself that aquatic types are decidedly inferior to the terrestrial; the marine inferior to the lacustrine and fluviatile ones; that those which live upon the main land and burrow under ground are inferior to those which live above ground; that nocturnal types are inferior to diurnal types; and that under otherwise similar circumstances representatives of one and the same group, which differ in these respects, have a higher and lower rank, in accordance with their extemal circumstances; so much "so, that where we have no other guide, an influence respecting their natural position may be fairly derived from their conditions of life.

It will thus be obvious that as soon as we introduce simultaneously into our classification considerations derived from all these different sources; as soon as we allow the embryonic development, geological succession, geographical distribution, and relation to the natural elements, to assist us in our efforts to assign to all animals a natural position in one great system, we shall be able to sketch a far more complete picture of the great diversity which exists in nature than if we allow ourselves to be guided chiefly by anatomical data; and my object at present is mainly to urge the necessity of studies in these different directions, with a view of improving our classification, and to insist upon the necessity of keeping, at the same time, in view, all these facts, whenever we attempt to form a correct idea of the manifested relations which exist throughout the creation, from the earliest period of the existence of animals up to the present day, betw een all their different types. 


\section{ON THE STRUCTURE OF THE HALCYONOID POLYPI.}

After removing the so-called Hydroid Polypi from the class of Polypi, to place them among Medusie, and the Bryozoa being referred to their true natural position among Mollusca, the class of Polypi contains only two natural groups of animals, the Actinoid Polypi, and the Halcyonoid Polypi.

Having, on a former occasion, given an account of my investigations, of the former group, I will now proceed to make some remarks upon the Halcyonoid Polypi of the United States, which I have had an opportunity to examine. They belong to three different genera.

\section{Renilla.}

One of these genera is the well known Renilla reniformis, which is extremely abundant on the Southern shores of the United States.

Though this genus is already well characterized, I have made upon it some remarks which may not be without interest.

Like the other genera of the family of Pennatuloid Polyps, they have a soft distinct axis, with a terminal kidney-shaped flat disk, spreading horizontally upon the vertical stem, so that its plane is at right angles with the stem, though the two halves are symmetrical upon the longitudinal diameter of the upper part of the axis. The axis, and also the disk, are hollow, and their cavities communicate freely with each other. In their expanded state, these cavities are filled with water by means of which they swell to a very remarkable extent, so much so that the disk may be enlarged to twice its diameter, and the peduncle of the stem to four times its height in an expanded state, when compared with its utmost state of contraction. When expanded, the stem stands upright, sunk in sand, its lowest extremity swollen into an oblong bulb, somewhat compressed laterally. The middle part of the stem is more cylindrical ; but in its upper part, it again enlarges into a sort of funnel, compressed laterally, extending with its prominent diameter, under the lower surface of the disk. The disk itself, is kidney or heart shaped, thicker in the middle, when swollen, and growing thinner towards the edges. Its lower surface is smooth at the stem, but there is a sort of radiation observed upon it, extending from the summit of the stem towards the margin, and corresponding to the linear radiating arrange- 
ment of the isolated animals, upon the upper surface of the disk. There are no polypi arising either from the stem, or from the lower surface of the disk; they all arise from the upper surface and edge. The isolated polypi arise from a softer area, in the form of octagonal tubes, elongated more or less when expanded, and terminating with a crown of eight lobed tentacles. These tentacles are arranged symmetrically upon the sides of an oblong oral aperture, three on each side of the mouth, and one in advance, and one behind; so that notwithstanding the apparent uniformity of the tentacles, there is a slight indication of bilateral symmetry in their arrangement, particularly marked by the oblong form of the opening of the mouth. The whole body is purplish red, of a very vivid color; the lowest extremity of the stem only is more yellowish, as is also the prominent angle of the funnel under the disk. The polypi themselves are bluish white, of a very delicate transparent appearance, lightly dotted with brown specks, forming a ring under the crown of tentacles, and two brown stripes upon the upper surface of each tentacle near the edges, broader toward the mouth, and tapering between the lobes of the tentacles. The cavity of these individual animals is divided into eight partitions, by longitudinal folds of their walls, and to these folds the digestive cavity is adherent above, but it opens free into the main cavity of the buds, in its lower part. There is no division, no partition at the bottom of the individual polypi, so that the food which has been digested in the upper alimentary sack, as soon as it is emptied into the main tube of each polyp, passes into the main cavity of the disk, and is circulated, not only in that cavity, but also within the main carity of the stem. The water, also, which distends the whole body, is introduced through the mouth of the individual polyps, and expelled through the same aperture when the body contracts. This animal has a very remarkable phosphoresence. It shines at night with a golden green light of a most wonderful softness. When excited, it flashes up more intensely, and when suddenly immersed into alcohol, throws out the most brilliant light. The stem has no solid support at all, as is the case with several other genera of the same family, but there calcareous spiculæ arranged in a radiating manner in the disk, and a few clusters of them at the base, and at the summit of the body, of each individual animal, situated in the spaces corresponding to the intervals between the lobed tentacles.

I have collected hundreds of specimens of this species upon the beaches of Sullivan's Island, in the bay of Charleston, South-Caroli- 
na, and also on the beaches south of Savannah, in Georgia, upon Warsaw Island.

\section{Halcyonium.}

The genus Halcyonium is usually spelled Alcyonyum, but this is incorrect.

I am not aware that any species of this genus has as yet been noticed upon the shores of the United States. In August, 1847, I dredged, however, a very handsome specimen, off Cape Cod, belonging to this type. It was attached to a loose shell of Mytilus Modiolus, upon the concave side of the shell, and seemed to differ from the known species of that genus, in having a proportionally small body, from which rose a cluster of long tubular individual polypi, each of which was nearly as long as the greatest diameter of the common base, from which they arose. When fully expanded, the individual polypi were tubular, cylindrical, slightly contracted under the tentacles, which spread in the form of an octagonal star, the lobes stretching slightly outside, and somewhat arched and downward. The form of each tentacle was conical, with a rounded tip; the lobes of the margin were proportionally not very deep; the odd terminal lobe larger than the lateral ones, the relative size of which was gradually less from the tip of the tentacles to its base. The mouth was slightly oblong, without folds, and below it hangs a cylindrical main digestive cavity extending for about one-fourth of the whole length in the expanded state of the tube, but occupying nearly one half of its length when distended by food in the contracted state of the animal.

The main cavity of the body is subdivided by eight prominent folds into as many imperfect partitions, shut from each other in the region of the stomach by their adherence to its outer surface. The substance of the body is rather consistent. The main bulk, from which the individual polypi arise is especially tough, being supported by numerous calcareous spiculæ, spread irregularly through its mass; but even the individual polypi are of tough substance, less moveable than those of Renilla, and expanding and contracting very slowly, while the polypi of Renilla are rather active. In consequence of this toughness of the substance, it was rather difficult to ascertain the internal arrangement of the parts, and to trace the circulation within the main cavity. I could however, satisfy myself that there are four ovarian bunches hanging from the inner projecting margin of 
the lateral folds, projecting into the cavity below the stomach; and a few eggs were still suspended to those bunches, which consisted of curled threads, coiled irregularly into four bunches. Besides these, there were two other threads hanging more loosely from two other partitions, which, probably were spermatic cords, though I could not detect any spermatic cells in connection with them. But the difference in the aspect of these threads, when contrasted with those from which the eggs hang, will scarcely leave any doubt as to their real nature. The fluid contained in the main cavity circulates regularly up and down between the partitions, and the currents extend into the tentacles and follow up the sinuosities of their lobes to the summit of the tentacles, returning in the opposite direction.

The movements of the individual polyps are regulated by bundles of contractile fibres extending along the partitions in the main wall of the body. These bundles are attached above and below to clusters of calcareous spiculæ, which are arranged in a regular order in the form of prominent cords within the outer wall of each partition, and upon the outer wall of each tentacle, at its base. These spiculæ are microscopic stems of a ragged appearance, formed, probably, by the reunion of a number of calcareous crystals developed in distinct cells, and united together in a somewhat regular manner, so as to form longitudinal stems with irregular projections upon their surface. Numbers of these little stems converge, in two parallel rows with their tips towards the tip of the tentacles, and others from the base assume a similar arrangement, and form larger cones around the base of the tube of the animal.

The point of insertion of the contractile fibres is in the narrow angles between those clusters, and they rise from the base of the tube upwards to the base of the tentacles, thus extending over the whole length of that part of the tube which is most contractile and retractile.

It remains to be seen whether the specimen of this animal which fell into my hands was quite full grown; for it is possible that the cluster observed was the beginning of a larger body, to be formed by the addition of a greater number of individual polypi growing out of the common base.

Should it be found, upon further investigation, that this type is a permanent combination, and that the stalk never grows to a bulky mass, and that the polypi arising from it are always proportionally so much larger than the stem itself, it may constitute a generic type 
intermediate between Halcyonium proper and Renilla. I have, at least, never seen the indivirlual polyps disappear entirely under the surface of the body, as we know to be the case among the true fleshy Halcyoniums.

For the distinction of the species, I shall propose the name of Halcyonium carneum, designating its flesh-color, and also the greater softness of the bulk when compared with the ordinary Halcyoniums.

\section{Gorgonia.}

The third genus of the Halcyonoid Polypi which occurs along the shores of the Southern States is the genus Gorgonia, with its many species about the Florida Keys, one of which is very common as far north as the Carolinas. Of this species I have had repeatedly an opportunity to examine living specimens with their expanded animals. The genus is well characterized by having a horny solid stem attached by a spreading base to solid bodies at the bottom of the sea.

The species vary greatly in the manner in which this stem branches and in the combination of these branches into a spreading shrub-like growth, with distinct branches or fan-like flat expansions and anastomosing branches. Although there seems to be no regularity in the distribution of the individual polyps upon the main stem, there is, nevertheless, one circumstance which should not be lost sight of, and requires further investigation fully to appreciate its meaning. It will be observed, indeed, that upon one side of the stem there is a deep furrow following the direction of the branches, as well as that of the main stem, and so assigning a peculiar character to one side of the branches. But how this furrow is formed I have not been able to ascertain. No polyp rises from its depression. nor even from its margin. They uniformly spring up from the plain surface of the branches in the shape of short tubes expanding into eight, lobed, rounded tentacles, supported at their base by calcareous spiculæ. The mouth is so regular as not to afford the means of distinguishing the longitudinal axis.

Even without taking into consideration the various modes in which the individual polyps are combined to form a regular kidney-shaped disk, as in Renilla, or an irregular spreading body, as in Halcyonium, or a branching stalk, as in Gorgonia, we find in the structure of the individual polypi differences which sufficiently characterize these genera in the form of their tentacles. In Renilla the isolated 
tentacles are elongated and lobed only towards their extremity and upon part of their sides. In Halcyonium the tentacles are triangular and the longer lobe is terminal, while in Gorgonia the tentacles are rounded and the lobes more uniform. The species of Gorgonia which I have examined is Gorgonia virgulata. The numerous varieties which occur in Charleston Harbour should induce some Naturalist to enter upon a very minute investigation of the structure and development of that species, in order fully to ascertain what are the changes which it undergoes with age, and what are the natural limits of the species in this genus; for the species are so numerous, and they all seem to vary so much, that until a complete monographic investigation of one species has been made, it will be impossible to determine with precision foreign species which have not been observed carefully in a fresh state.

The variations of color which occur in this species are very remarkable. I have seen specimens growing together, and undoubtedly belonging to the same species, which were light yellow, and almost white, passing into a dark yellow tint; others light orange; others dark orange; then light purple varieties; others almost pink, or bluish purple, and some perfectly white as pure chalk. It is really a wonderful sight to behold these varieties growing together in clear water and spreading over considerable surfaces with all these colors mingled. From the same stone specimens will arise of all these different hues. At times stems of one color will grow from the bore of stems of other colors; but I have never been able to discover a branch of another color upon the same stem, or the stems of different colors arising from the same base. Wherever this seems to be the case, upon close examination it is always found that the parts differing in color have distinct origins, although they may grow upon each other, as they all grow upon stones or other sub-marine bodies.

Although it may be difficult to raise eggs and see the whole process of development, it is so very easy to collect a series of specimens in all stages of growth, from their first appearance in the shape of minute buds upon the surface from which layer specimens arise, that, for a persevering observer on the spot there will be no difficulty in tracing the whole range of the metamorphoses. I would only mention what an examination of a few days has enabled me to observe, that the new stems sprout in the form of stiff, erect, simple stems; that more advanced specimens show a simple bifurcation, which will successively give rise to a greater number of branches. 
At first, the young polypi have only a narrow base of attachment, and we find only in larger ones that the stem spreads into a wide flat base, by which it is attached to the ground. The mode of development of this base might also be easily ascertained by a series of specimens carefully collected for that purpose, and placed side by side, to see the changes in the development. It is to be hoped that some intelligent young naturalist at the South will supply the deficiency of these observations, gathered during a hurried excursion.

Whether this species occurs in other parts of the ocean beyond the limits of the United States, is a point which I am unable to determine. It may be that the indications of other localities in which Gorgonia virgulata is said to occur are either incorrect or have reference to closely allied representative species growing in other parts of the world. 


\section{ON THE MORPHOLOGY OF THE MEDUS质.}

Since it has been ascertained that the Medusæ pass through different forms in their various metamorphoses, and that their changes are further complicated by an alternation of generations, it is a matter of importance to learn how far the Polypoid stems from which free Medusæ arise are themselves allied to Medusæ, or to Polypi. As long as the so-called Hydroid Polypi were supposed to be perfect animals, propagating themselves under the same forms, it was natural, from their general appearance, that they should be considered as a peculiar type among Polypi, and that the question of their structural relations to Medusæ should not even be raised. But now it is a matter of the first importance to ascertain whether in this Polypoid form their structure is more closely related to Medusæ than to Polypi, and whether their relation to Polypi is merely analogical, and not truly structural. I have investigated this subject at some length, and satisfied myself that even in an anatomical point of view the so-called Hydroid Polypi should be referred to the class of Medusæ, aud that their resemblance to Polypi is simply the result of a close analogy, and not of true affinity, as the Morphology of their parts indicates a very close affinity to Medusæ.

In order to appreciate fully this statement, it is necessary to remember that true Polypi have a distinct digestive sac hanging into the large main cavity of the body, and that this cavity is sub-divided into more or less distinct compartments by partitions projecting inwardly. Again, the tentacles arise from the upper margin of the main cavity, and are in no instance appendages of the margin of the mouth. In Medusæ, on the contrary, the main cavity is undivided, and where there is a peripheric prolongation it assumes the shape of circumscribed tubes, penetrating into the substance of the body. Again, the tentacles are, at least, of two kinds-those, which arise from the margin of the body, and others which are prolongations of the margin of the mouth.

If, with these facts before our minds, we now attempt a comparison of the so-called Hydroid Polypi with either Medusæ or true Polypi, we shall find, in the first place, that the main cavity in Hydroid Polypi is not divided by radiating partitions into distinct compartments, as is the case in true Polypi, and that their buds at least, if not the main cavity of the system, have radiating tubes arising from 
the digestive sac and following the walls of the main cavity. But what is more striking and characteristic in Hydroid Polypi is the circumstance that the main bulk of the body is constantly well circumscribed, and its margin or surface provided with peculiar tentacles, while the proboscis or mouth assumes various forms, projecting sometimes in the shape of a movable tube, or in the form of a prominent tubercle, with a central oral opening, encircled by a row, or several rows, of peculiar tentacles or fringes. These oral appendages may be compared morphologically to the fringed lobes arising from the margin of the mouth in true Medusæ, while the tentacles of the margin and surface of the body bear the closest resemblance in position and relations to the tentacles arising from the margin of the disc in true Medusæ.

In these respects, therefore, the Hydroid Polypi are more closely allied by structure to true Medusæ than to Polypi, and their resemblance to Polypi it chiefly derived from the elongation of their verticle axis, the development of a peduncle of attachment, and the formation of buds which remain attached to the main body, and give it the appearance of a branching Polypi, while true Medusæ are, from the beginning of their independent development, free moving animals . But it has been already ascertained in so many families, among Echinoderms as well as among Polypi, that there are types attached by stems, and others which are entirely free, notwithstanding their closest structural relations. That this fact can be no objection, but, on the contrary, an argument in favor of the view that Hydroid Polypi, with their medusine structure, should be considered as true Medusæ, provided with a stem, rather than a peculiar family among Polypi, and even should there be among them forms which never produce free Medusæ, as soon as they present those peculiar combinations of character which occur only among Medusæ, we shall be inclined to remove them from Polypi, and to place them among true Medusæ. The medusoid character of the crown in Tubularia is particularly obvious, and it requires little familiarity with the different forms of Medusæ to feel satisfied that the inner prominent cylindrical bulb which projects above the crown of large tentacles, and is provided on its summit with another row of shorter tentacles, is truly analogous to the central proboscis of many discoid Medusæ, such as Gorgonia and Sarsia, while the large tentacles around the central cup corresponds to the marginal tentacles of Medusæ. The stem itself is analogous to the short stem by which the bulb of young Medusæ is 
connected with the Hydroid Polyp from which they arise. This analogy further sustains the view that Hydroid Polypi are true Medusæ, inasmuch as here we have a crown of medusoid structure resting upon a stem similar to the stem of attachment of young Medusæ, which is only much more elongated, and from which similar branches may bud.

The analogy of some genera of Hydroid Polypi, such as Coryne and Syncoryna, to Medusæ, is apparently more remote, from the circumstance that the tentacles are scattered around the surface of the terminal bulb; but it requires only a close comparison of the mode of formation and increase of the tentacles in those genera in which they form a regular whorl to satisfy the observer that even in those Medusæ in which the regular crown of tentacles seems to form strictly a whorl, the tentacles in their successive development do not arise from the same level, but that there are some which are inserted nearer the centre of the axis than others; so much so that an elongation of the axis upon which they stand would produce an arrangement similar to that which we notice in Coryne and Syncoryna, where they are regularly scattered. Even in the latter genus the analogy is complete, for the uppermost end of the main bulb terminates with a regular opening, surrounded with minute fringes, though this aperture seems to have been overlooked by former observers. Though a mouth is mentioned in the characteristics of Coryne, in Syncoryna it seems to have escaped attention. I may add that there is a remarkable correlation between the number of tentacles which exist nominally upon a terminal bulb of Syncoryna and the nominal number of radiating tubes and tentacles which are developed in the little Sarsia produced from that Hydroid Polyp. Syncoryna has generally sixteen tentacles, four times as many as the free Medusæ to which it gives birth.

In no Hydroid Polyp is the structure of the tentacles more closely allied to that of some of the naked-eyed Medusæ than in Syncoryna, for their club-shaped tentacles, with lasso cells, remind us most distinctly of the tentacles of Slabberia; and, so far as these comparisons are conclusive, there remains no doubt in our mind that, from their structure and Morphology, the so-called Hydroid Polypi must be considered as true Medusæ, among which they constitute a type analogous to the stalked Crinoid among Echinoderms; an analogy which is the more remarkable, as in their ultimate generation Hydroid Polypi produce free Medusæ, while the Comatulæ arise from the Cri. noids provided with stems. 







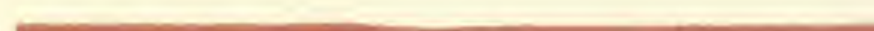


